\title{
Therapeutics Progression in Pancreatic Cancer and Cancer Stem Cells
}

\author{
Minwei Zhou*, Yantian Fang*, Jianbin Xiang\#, Zongyou Chen\# \\ Department of General Surgery, Huashan Hospital, Fudan University, Shanghai, China \\ Email: ${ }^{\text {czyshhs@126.com }}$
}

Received 12 January 2015; accepted 22 February 2015; published 25 February 2015

Copyright @ 2015 by authors and Scientific Research Publishing Inc.

This work is licensed under the Creative Commons Attribution International License (CC BY).

http://creativecommons.org/licenses/by/4.0/

(c) (i) Open Access

\begin{abstract}
Pancreatic cancer (PC) is one of the most lethal malignant tumors, which often result from diagnoses of advanced stages and ineffective therapies. A main reason for this extremely poor prognosis is the cancer's tendency to invade adjacent tissues and metastasize to regional lymph at a relatively early stage. Nowadays, the resistance to conventional chemotherapy is becoming crucial in poor clinical outcomes of PC. In order to improve the prognosis and clinical outcomes of PC, there is a pressing need to develop new therapeutic strategies not only aimed at preventing invasion and metastasis, but also improving the resistance of chemotherapies. The resistance to conventional therapeutic agents in cancer may be sustained by a fraction of cancer cells within the tumor, which is called the cancer stem cells (CSCs). Combined therapies targeting CSCs and their progenies may represent the most promising approach for the future treatment of patients with PC.
\end{abstract}

\section{Keywords}

Pancreatic Cancer, Cancer Stem Cells, Cancer Therapy

\section{Introduction}

Pancreatic cancer (PC) has one of the worst prognoses of any major malignancy (6.7\% 5-year survival) [1]. Despite recent improvements in surgical and chemotherapeutic approaches, PC continues to have a poor prognosis due to the lack of early symptoms, which results in advanced stage and metastatic states of PC patients and makes their malignancy inoperable. Moreover, drug-resistance is also a main reason for the dismal prognosis with an average overall median survival of 4 - 6 months in PC patients [2] [3]. Nowadays, PC is the fifth most common cause of cancer death yearly in the United States and seventh cancer death in China [1] [4]. According to the report of Nation Cancer Institute (NIH), the number of new cases of PC was 12.3 per 100,000 men and women per year during 2007-2011, while 10.9 per 100,000 men and women dead of PC every year during

${ }^{*}$ Contributed equally.

${ }^{\#}$ Corresponding authors.

How to cite this paper: Zhou, M.W., Fang, Y.T., Xiang, J.B. and Chen, Z.Y. (2015) Therapeutics Progression in Pancreatic Cancer and Cancer Stem Cells. Journal of Cancer Therapy, 6, 237-244. http://dx.doi.org/10.4236/jct.2015.63026 
2006-2010 [1].

Recent studies have shown that a small group of cells possess stem cell-like characters in various cancers [5]-[7]. These cells have been called cancer stem cells (CSCs) because of their stemness. CSCs have similar features as stem cells, including pluripotency with the function of self-renew and differentiation. CSCs mainly remain in the G0 phase of the cell cycle so that they are less sensitive to traditional radiotherapy and chemotherapy than proliferating cells [8]. Therefore, there is an emerging need to develop new strategies against CSCs. During the past few years, it has been demonstrated that CSCs are closely related to PC and play an important role in targeting therapeutic strategies [9] [10].

In this article, we reviewed the research status of pancreatic CSCs and recent progressions in CSC-related therapeutic strategies.

\section{Cancer Stem Cells and Tumors}

CSCs have been proved to possess the function of self-regenerate, proliferate and have multiple differentiation potentials [11]. They can differentiate to cancer cells and produce different phenotypes of non-tumorigenic tumor cells to enlarge tumor mass as well. They are also considered to be the only cells with metastatic ability in the tumor cell subset [12]-[14].

CSCs were first found in patients with acute myeloid leukemia. Bonnet and Dick found that some hematopoietic stem cells, which were similar to CD34+ CD38+ cells from tumor tissues, could self-renew, self-regenerate and become xenografts in nude mice [15]. Xenograft formation in nude mice was regarded as the gold standard of CSCs in cancer tissues. Breast cancer is one of the earliest tumors discovered to have CSCs. Al-Hajj and colleagues isolated a CD44+/CD24-/low cell line from breast cancer, which can form tumors in nude mice [16]. Ignatova et al first isolated CD133+ CSCs in human brain tumors, and found that an injection of CD133+ tumor cells can differentiate and proliferate into brain tumor [17]. However, even with injection of up to 500 times of CD133- cancer cells, there was no tumor formation. This provided strong evidence of the existence of CSCs. Thereafter, researchers proved the existence of CSCs in many solid tumors, including glioma [18], multiple myeloma [19], pancreatic cancer [20], colon cancer [21], liver cancer [22], prostate cancer [23], head and neck squamous cell carcinoma [24], malignant melanoma [25], and ovarian cancer [26].

Like the normal stem cells, CSCs are the foundation and basis of the tumors. The expression of cancer-suppressing genes within CSCs is inhibited, and that of Sonic hedgehog (SHH), Notch, Wnt/ß-catenin, and Hox signaling pathway is activated [27]-[30]. CSCs are regarded to be become drug resistant during conventional chemotherapy, and migrate and metastasize rapidly into novel tumors. All these findings are helpful for understanding tumors more comprehensively and developing more targeted cancer therapy.

\subsection{Identification of Pancreatic Cancer Stem Cells}

CSCs have been identified by a variety of biomarkers, some of which were previously associated with normal stem cells in the pancreas. But the detailed function of these markers remains uncertain.

\subsection{CD44, CD24, EpCAM}

CD44, CD24 and EpCAM (also called ESA) are often regarded as cell surface markers of CSCs in PC. Li first described population of pancreatic stem cells in 2007 [31]. Researchers injected a subpopulation of CD44+ CD24+ ESA+ cells from pancreatic ductal adenocarcinoma (PDAC) into immunodeficient mice and induced tumors, while their triple negative counterparts did not show tumorigenic capacity. In their studies, this population of CD44+ CD24+ ESA+ cells could initiate tumors much easier in 50\% of transplanted mice. In contrast, as many as 100 -fold triple negative cells were required to form tumors.

These triple positive cells could also re-establish the cell-surface profile of markers of the original tumors, which result from cell-renew and differentiation into triple-negative or single- and double-positive populations [32]. This process was considered to be related with SHH pathway, which is less activated in normal pancreatic cells, unsorted pancreatic cancer cells, and triple-negative cells. These findings indicated that this pathway might be important for the tumor-promoting functions of these cells.

\subsection{CD133}

CD133 could be found in CSCs from various tumors [33] [34]. Like CD44+ CD24+ ESA+ cells, CD133+ pan- 
creatic CSCs also showed more aggressive behavior compared with CD133- cells, which include increased cell proliferation, migration, tumor invasion, and especially the presence of pancreatic stromal cells [35]. Compared with CD44 and CD24 positive cells, CD133+ cells also show higher tumorigenic and metastatic potential [36]. Injecting $5 \times 10^{2} \mathrm{CD} 133+$ cells into nude mice could induce tumor formation while no tumor growth was detected after inoculation of up to 2000 folds of CD133- cells [35]. Hermann also detected an overlap between CD133+ and CD44+ CD24+ EpCAM+. However, none of the puring procedures for CSCs is currently capable of identifying single tumorigenic cells [35].

\subsection{CXCR4}

CXCR4 has been implicated in mediating pancreatic cancer invasion and metastases. Hermann and colleagues discovered a certain subpopulation of migrating both CD133 and CXCR4 positive CSCs, which is essential for metastasis in PC [35]. As the receptor for stromal-derived factor-1 (SDF-1/CXCL12], CXCR4 can strongly induce the migration for CD133+ cancer cells in vitro. And the blockage of CD133 +/CXCR4+ cells could prevent metastasis of tumor xenografts in mice [35]. This indicates that modulating the SDF-1/CXCR4 axis might be potential pharmaceutical strategies in inhibiting metastasis of CSCs.

\section{5. c-Met}

c-Met, belongs to the group of receptor tyrosine kinases, is one of the novel detected pancreatic CSC markers. With the function of mediating cell growth, angiogenesis and metastasis, c-Met is named as the mesenchymalepithelial transition factor and membrane receptor (MET) [37]. Combined with its physiological ligand, the hepatocyte growth factor (HGF], c-Met is required for normal mammalian development and plays an important role in epithelial-mesenchymal interactions during organ morphogenesis. Using xenografts and injecting pancreatic cancer cells from patients, Li et al show that these cells express high levels of c-Met. c-Met was particularly informative when combined with CD133 or CD44. Moreover, it was interesting that using both c-Met and CD44 could identify a population of cells with strongest tumorigenic potential. These double-positive cells could generate subcutaneous tumors and were highly metastatic [38].

It was also reported that inhibition of c-Met activity with the kinase inhibitor XL184 (cabozantinib) could reduce tumorsphere formation, growth of tumor xenografts, and metastasis in intracardiac injection models [39]. This indicates that c-Met activity is required to maintain a CSC population.

\subsection{ALDH1 (Acetaldehyde Dehydrogenase-1)}

ALDH1, a marker of normal and malignant breast stem cells [40] and lung CSC [41], has also been used for isolating tumorigenic cells in the human pancreatic line L3.6pl [42]. ALDH1 expression could predict for poor outcome and ALDH1+ cells presented enhanced migratory and invasive potential compared to ALDH1-cells [43]. ALDH1 could also be functional marker of pancreatic CSCs. Studies suggest that high expression of ALDH1 protects pancreatic cancer cells from chemotherapy-induced cell death [44]. Xenograft tumors exposed to gemcitabine become enriched for ALDH1-positive cells [45], indicating that they can withstand chemotherapy.

\section{Targeting Therapies against Pancreatic Cancer Stem Cells}

Nowadays, the therapeutic strategies against PC are facing two main problems. One of them is drug resistance. Recent researches have revealed that CSCs, especially pancreatic CSCs, play crucial roles in drug resistance which often impairs the successful use of chemotherapies [35] [46]-[48]. Zhang et al. found that pancreatic cancer stem-like cells were more resistant to gemcitabine, commonly used against pancreatic carcinoma, and those cells were more invasive [49]. Pancreatic CSCs were proved to contribute to drug resistance of gemcitabine as well [50]. Another problem is that most therapies for pancreatic cancer do not affect pancreatic CSCs, which can then re-establish tumors after treatment. New approaches are therefore needed to debulk existing tumors and eliminate pancreatic CSCs, to prevent relapse. So targeting therapies, which could eliminate pancreatic CSCs and reduce drug resistance, are emerging needs in PC therapies.

\section{Recent Approaches for Targeting Pancreatic Cancer Stem Cells}

Minnelide, a water-soluble prodrug of triptolide, is currently under phase I clinical trial. By decreasing CD133+ 
tumor-initiate cells (TICs or CSCs) as well as non-TIC population, Minnelide could reduce tumor burden, which might point out a potential and effective therapy against PC [51].

Sulforaphane could inhibit the growth of pancreatic CSCs orthotopically implanted in NOD/SCID mice by inhibiting SHH pathway and also inhibits the marker of EMT in human pancreatic CSCs [52].

The dual endothelin1/VEGF signal peptide receptor, DEspR, is detected in microvessels and tumor cells in PDAC. It can be found in CSCs isolated from PDAC-Panc1 cells as well. Researches demonstrated that DEspRinhibition could decrease Panc1-CSC xenograft tumor growth in nude rats by impacting CD133+ CSCs, suggesting that DEspR-inhibition defines a novel targeting therapy for pancreatic cancer [53].

Disulfiram, an irreversible inhibitor of ALDH, was found to play a key role in resistance to anticancer therapies for PDAC. Kim et al found human PDAC-derived cells, expressing high levels of ALDH, could show CSC features. Disulfiram is sensitive to this gemcitabine-resistant subpopulation and removes ALDH-high cancer cells and inhibits tumor growth [54].

CSCs are enriched in the side proportion (SP) cells, which overexpresss stem cell markers as well as pluripotency maintaining factors, such as Nanog, Sox2, Oct4, c-Myc, signaling molecule Notch1, and drug resistant gene ABCG2. Some scientists established a combination of Sox2/Oct4/c-Myc targeting agent, which could suppress all CSC properties and phenotypes, and reduce the tumorigenic capability of the SP cells and the resistance to conventional chemotherapy [55].

Inhibiting c-Met with XL184 or Alk-4/7 with SB431542 [56] reduces the number of CSCs in tumors and has synergistic effects with gemcitabine. While Gemcitabine treatment results in an increase of the c-Me-thigh CD44+ population, c-Met inhibition with XL184 leads to a decrease in c-Methigh CD44+ cells. Combination treatment prevents the increase in the CSC population observed with Gemcitabine alone and also contributes to a decrease in c-Methigh CD44+ population, suggesting that XL184 targets the CSC population specifically.

\section{Immunotherapy against CSCs}

Nowadays, a series of immunotherapies are induced and directly targeting towards specific antigens expressed by tumor cells including CSCs. A recent study by Huang and colleges shows an anti-CD3/anti-CD133 bispecific antibody (BsAb) bounding with cytokine-induced killer (CIK) cells could target and kill CD133 high CSCs. The killing of CD133 high pancreatic (SW1990) by the effect cells (BsAb-CIK cells) was significantly $(\mathrm{p}<0.05)$ higher than the killing by the parental CIK or by CIK cells bound only with anti-CD3 (CD3-CIK) and inhibited CD133 high tumor growth significantly. The findings introduce a novel immunotherapy for patients with cancer containing CD133 high CSCs by selectively targeting this population [57].

Immunotherapy with unconventional T cells such as $\gamma \delta \mathrm{T}$ cells is based on their potent HLA-nonrestricted cytotoxicity against different tumor entities and their additional capacity to recognize and present antigens to $\alpha \beta$ T cells [58] [59]. Oberg [60] demonstrated how bispecific antibodies that selectively recruit $\gamma \delta$ T cells to tumor antigens expressed by cancer cells illustrate the tractable use of endogenous $\gamma \delta$ T cells for immunotherapy. They isolated $\gamma \delta$ T cells from patients with PDAC tumor infiltrates lyse pancreatic tumor cells after selective stimulation with phosphorylated antigens and designed bispecific antibodies that bind CD3 or V $\gamma 9$ on $\gamma \delta \mathrm{T}$ cells and Her2/neu (ERBB2) expressed by pancreatic tumor cells. Both antibodies enhanced $\gamma \delta$ T-cell cytotoxicity with the Her2/Vg9 antibody also selectively enhancing release of granzyme B and perforin and reduced growth of pancreatic tumors grafted into SCID-Beige immunocompromised mice.

As mentioned above, high level of ALDH was related with pancreatic CSCs. Visus et al. [61] used ALDH as a marker for identifying and selectively targeting pancreatic CSCs as well. They generated ALDH1A1-specific CD8+ T cells in order to eliminate ALDH+ CSCs, which induced growth inhibition of CSCs and reduction of metastasis. However, ALDH1A1-specific CD8+ T cells are not CSCs-specific. They could target normal ALDH+ stem cells as well.

\section{Conclusion}

The discovery of pancreatic CSCs has introduced an important concept to cancer biology. Targeting therapies for cancer treatment are much more important when conventional therapies are effortless. According to recent studies, pancreatic CSCs appear to be critical for the processes of cancer cell invasion and metastasis. Therefore, targeting strategies for pancreatic CSCs could be crucial for the prevention of cancer progression and metastasis. However, the mechanism of the resistance of Pancreatic CSCs to radiation and chemotherapy still remains un- 
clear. We also should keep on sighting pancreatic CSCs gene expression profiles and the overall complexity of the tumor microenvironment.

\section{Acknowledgements}

M. W. Zhou and Y. T. Fang have equally contributed to this work. They are joint first authors. This work was supported by a Grant from Shanghai Science and Technology Department of Medicine guiding biomedical projects (no. 134119a1400) and a grant from Research Fund for the Doctoral Program of Higher Education (New Teacher) (no. 20130071120048).

\section{References}

[1] Bethesda, M.D. SEER Cancer Statistics Factsheets: Pancreas Cancer. National Cancer Institute. http://seer.cancer.gov/statfacts/html/pancreas.html

[2] Vincent, A., Herman, J., Schulick, R., et al. (2011) Pancreatic Cancer. The Lancet, 378, 607-620. http://dx.doi.org/10.1016/S0140-6736(10)62307-0

[3] Conroy, T., Gavoille, C. and Adenis, A. (2011) Metastatic Pancreatic Cancer: Old Drugs, New Paradigms. Current Opinion in Oncology, 23, 390-395. http://dx.doi.org/10.1097/CCO.0b013e3283473610

[4] Chen, W.Q., Zheng, R.S., Zhang, S.W., et al. (2014) The Incidences and Mortalities of Major Cancers in China, 2010. Chinese Journal of Cancer, 33, 402-405.

[5] Lee, C.J., Dosch, J. and Simeone, D.M. (2008) Pancreatic Cancer Stem Cells. Journal of Clinical Oncology, 26, 28062812. http://dx.doi.org/10.1200/JCO.2008.16.6702

[6] Hermann, P.C., Mueller, M.T. and Heeschen, C. (2009) Pancreatic Cancer Stem Cells—Insights and Perspectives. Expert Opinion on Biological Therapy, 9, 1271-1278. http://dx.doi.org/10.1517/14712590903246362

[7] Ischenko, I., Seeliger, H., Kleespies, A., et al. (2010) Pancreatic Cancer Stem Cells: New Understanding of Tumorigenesis, Clinical Implications. Langenbeck's Archives of Surgery, 395, 1-10. http://dx.doi.org/10.1007/s00423-009-0502-z

[8] Chuthapisith, S., Eremin, J., El-Sheemey, M., et al. (2010) Breast Cancer Chemoresistance: Emerging Importance of Cancer Stem Cells. Surgical Oncology, 19, 27-32. http://dx.doi.org/10.1016/j.suronc.2009.01.004

[9] Lonardo, E., Hermann, P.C. and Heeschen, C. (2010) Pancreatic Cancer Stem Cells-Update and Future Perspectives. Molecular Oncology, 4, 431-442. http://dx.doi.org/10.1016/j.molonc.2010.06.002

[10] Hermann, P.C., Bhaskar, S., Cioffi, M., et al. (2010) Cancer Stem Cells in Solid Tumors. Seminars in Cancer Biology, 20, 77-84. http://dx.doi.org/10.1016/j.semcancer.2010.03.004

[11] Clarke, M.F., Dick, J.E., Dirks, P.B., Eaves, C.J., Jamieson, C.H.M., Leanne Jones, D., et al. (2006) Cancer Stem Cells-Perspectives on Current Status and Future Directions: AACR Workshop on Cancer Stem Cells. Cancer Research, 66, 9339-9344. http://dx.doi.org/10.1158/0008-5472.CAN-06-3126

[12] Reya, T., Morrison, S.J., Clarke, M.F. and Weissman, I.L. (2001) Stem Cells, Cancer, and Cancer Stem Cells. Nature, 414, 105-111. http://dx.doi.org/10.1038/35102167

[13] Shigdar, S., Li, Y., Bhattacharya, S., O’Connor, M., Pu, C.W., Lin, J., et al. (2014) Inflammation and Cancer Stem Cells. Cancer Letters, 345, 271-278. http://dx.doi.org/10.1016/j.canlet.2013.07.031

[14] Marchesi, V. (2013) Breast Cancer: Mutations in Breast Cancer Stem Cells Correlate with Metastases. Nature Reviews Clinical Oncology, 10, 546. http://dx.doi.org/10.1038/nrclinonc.2013.146

[15] Bonnet, D. and Dick, J.E. (1997) Human Acute Myeloid Leukemia Is Organized as a Hierarchy that Originates from a Primitive Hematopoietic Cell. Nature Medicine, 3, 730-737. http://dx.doi.org/10.1038/nm0797-730

[16] Al-Hajj, M., Wicha, M.S., Benito-Hernandez, A., Morrison, S.J. and Clarke, M.F. (2003) Prospective Identification of Tumorigenic Breast Cancer Cells. Proceedings of the National Academy of Sciences of the United States of America, 100, 3983-3988. http://dx.doi.org/10.1073/pnas.0530291100

[17] Ignatova, T.N., Kukekov, V.G., Laywell, E.D., Suslov, O.N., Vrionis, F.D. and Steindler, D.A. (2002) Human Cortical Glial Tumors Contain Neural Stem-Like Cells Expressing Astroglial and Neuronal Markers in Vitro. Glia, 39, 193-206. http://dx.doi.org/10.1002/glia.10094

[18] Kim, Y., Wu, Q., Hamerlik, P., Hitomi, M., Sloan, A.E., Barnett, G.H., et al. (2013) Aptamer Identification of Brain Tumor-Initiating Cells. Cancer Research, 73, 4923-4936. http://dx.doi.org/10.1158/0008-5472.CAN-12-4556

[19] Matsui, W., Borrello, I. and Mitsiades, C. (2012) Autologous Stem Cell Transplantation and Multiple Myeloma Cancer Stem Cells. Biology of Blood and Marrow Transplant, 18, S27-S32. http://dx.doi.org/10.1016/j.bbmt.2011.10.036 
[20] Li, C., Lee, C.J. and Simeone, D.M. (2009) Identification of Human Pancreatic Cancer Stem Cells. Methods Mol Biol, Volume 568, 161-173. http://dx.doi.org/10.1007/978-1-59745-280-9_10

[21] O’Brien, C.A., Pollett, A., Gallinger, S. and Dick, J.E. (2007) A Human Colon Cancer Cell Capable of Initiating Tumour Growth in Immunodeficient Mice. Nature, 445, 106-110. http://dx.doi.org/10.1038/nature05372

[22] Yang, Z.F., Ho, D.W., Ng, M.N., Lau, C.K., Yu, W.C., Ngai, P., et al. (2008) Significance of CD90 Cancer Stem Cells in Human Liver Cancer. Cancer Cell, 13, 153-166. http://dx.doi.org/10.1016/j.ccr.2008.01.013

[23] Mateo, F., Fernandez, P.L. and Thomson, T.M. (2013) Stem Cells in Prostate Cancer. Archivos Españoles de Urología, 66, 475-486.

[24] Prince, M.E., Sivanandan, R., Kaczorowski, A., Wolf, G.T., Kaplan, M.J., Dalerba, P., et al. (2007) Identification of a Subpopulation of Cells with Cancer Stem Cell Properties in Head and Neck Squamous Cell Carcinoma. Proceedings of the National Academy of Sciences of the United States of America, 104, 973-978. http://dx.doi.org/10.1073/pnas.0610117104

[25] Fang, D., Nguyen, T.K., Leishear, K., Finko, R., Kulp, A.N., Hotz, S., et al. (2005) A Tumorigenic Subpopulation with Stem Cell Properties in Melanomas. Cancer Research, 65, 9328-9337. http://dx.doi.org/10.1158/0008-5472.CAN-05-1343

[26] Szotek, P.P., Pieretti-Vanmarcke, R., Masiakos, P.T., Dinulescu, D.M., Connolly, D., Foster, R., et al. (2006) Ovarian Cancer Side Population Defines Cells with Stem Cell-Like Characteristics and Mullerian Inhibiting Substance Responsiveness. Proceedings of the National Academy of Sciences of the United States of America, 103, 11154-11159. http://dx.doi.org/10.1073/pnas.0603672103

[27] Yasuda, H., Soejima, K., Watanabe, H., Kawada, I., Nakachi, I., Yoda, S., et al. (2010) Distinct Epigenetic Regulation of Tumor Suppressor Genes in Putative Cancer Stem Cells of Solid Tumors. International Journal of Oncology, 37, 1537-1546.

[28] Garner, J.M., Fan, M., Yang, C.H., Du, Z.Y., Sims, M., Davidoff, A.M. and Pfeffer, L.M. (2013) Constitutive Activation of Signal Transducer and Activator of Transcription 3 (STAT3) and Nuclear Factor $\kappa$ B Signaling in Glioblastoma Cancer Stem Cells Regulates the Notch Pathway. Journal of Biological Chemistry, 288, 26167-26176. http://dx.doi.org/10.1074/jbc.M113.477950

[29] Norris, L., Karmokar, A., Howells, L., Steward, W.P., Gescher, A. and Brown, K. (2013) The Role of Cancer Stem Cells in the Anti-Carcinogenicity of Curcumin. Molecular Nutrition \& Food Research, 57, 1630-1637. http://dx.doi.org/10.1002/mnfr.201300120

[30] Lobo, N.A., Shimono, Y., Qian, D. and Clarke, M.F. (2007) The Biology of Cancer Stem Cells. Annual Review of Cell and Developmental Biology, 23, 675-699. http://dx.doi.org/10.1146/annurev.cellbio.22.010305.104154

[31] Li, C.W., Heidt, D.G., Dalerba, P., Burant, C.F., Zhang, L.J., Adsay, V., et al. (2007) Identification of Pancreatic Cancer Stem Cells. Cancer Research, 67, 1030-1037. http://dx.doi.org/10.1158/0008-5472.CAN-06-2030

[32] Abel, E.V. and Simeone, D.M. (2013) Biology and Clinical Applications of Pancreatic Cancer Stem Cells. Gastroenterology, 144, 1241-1248. http://dx.doi.org/10.1053/j.gastro.2013.01.072

[33] Singh, S.K., Clarke, I.D., Terasaki, M., Bonn, V.E., Hawkins, C., Squire, J. and Dirks, P.B. (2003) Identification of a Cancer Stem Cell in Human Brain Tumors. Cancer Research, 63, 5821-5828.

[34] Miki, J., Furusato, B., Li, H.Z., Gu, Y.P., Takahashi, H., Egawa, S., et al. (2007) Identification of Putative Stem Cell Markers, CD133 and CXCR4, in hTERT-Immortalized Primary Nonmalignant and Malignant Tumor-Derived Human Prostate Epithelial Cell Lines and in Prostate Cancer Specimens. Cancer Research, 67, 3153-3161. http://dx.doi.org/10.1158/0008-5472.CAN-06-4429

[35] Hermann, P.C., Huber, S.L., Herrler, T., Aicher, A., Ellwart, J.W., Guba, M., Bruns, C.J. and Heeschen, C. (2007) Distinct Populations of Cancer Stem Cells Determine Tumor Growth and Metastatic Activity in Human Pancreatic Cancer. Cell Stem Cell, 1, 313-323. http://dx.doi.org/10.1016/j.stem.2007.06.002

[36] Lee, H.J., You, D.D., Choi, D.W., Choi, Y.S., Kim, S.J., Won, Y.S. and Moon, H.J. (2011) Significance of CD133 as a Cancer Stem Cell Markers Focusing on the Tumorigenicity of Pancreatic Cancer Cell Lines. Journal of the Korean Surgical Society, 81, 263-270.

[37] Michieli, P., Mazzone, M., Basilico, C., Cavassa, S., Sottile, A., Naldini, L. and Comoglio, P.M. (2004) Targeting the Tumor and Its Microenvironment by a Dual-Function Decoy Met Receptor. Cancer Cell, 6, 61-73. http://dx.doi.org/10.1016/j.ccr.2004.05.032

[38] Li, C.W., Wu, J.J., Hynes, M., Dosch, J., Sarkar, B., Welling, T.H., di Magliano, M.P. and Simeone, D.M. (2011) c-Met Is a Marker of Pancreatic Cancer Stem Cells and Therapeutic Target. Gastroenterology, 141, 2218-2227. http://dx.doi.org/10.1053/j.gastro.2011.08.009

[39] Herreros-Villanueva, M., Zubia-Olascoaga, A. and Bujanda, L. (2012) c-Met in Pancreatic Cancer Stem Cells: Therapeutic Implications. World Journal of Gastroenterology, 18, 5321-5323. http://dx.doi.org/10.3748/wjg.v18.i38.5321 
[40] Ginestier, C., Hur, M.H., Charafe-Jauffret, E., Monville, F., Dutcher, J., Brown, M., et al. (2007) ALDH1 Is a Marker of Normal and Malignant Human Mammary Stem Cells and a Predictor of Poor Clinical Outcome. Cell Stem Cell, 1, 555-567. http://dx.doi.org/10.1016/j.stem.2007.08.014

[41] Jiang, F., Qiu, Q., Khanna, A., Todd, N.W., Deepak, J., Xing, L.X., et al. (2009) Aldehyde Dehydrogenase 1 Is a Tumor Stem Cell-Associated Marker in Lung Cancer. Molecular Cancer Research: MCR, 7, 330-338. http://dx.doi.org/10.1158/1541-7786.MCR-08-0393

[42] Kim, M.P., Fleming, J.B., Wang, H., Abbruzzese, J.L., Choi, W., Kopetz, S., McConkey, D.J., Evans, D.B. and Gallick, G.E. (2011) ALDH Activity Selectively Defines an Enhanced Tumor-Initiating Cell Population Relative to CD133 Expression in Human Pancreatic Adenocarcinoma. PLoS ONE, 6, e20636. http://dx.doi.org/10.1371/journal.pone.0020636

[43] Rasheed, Z.A., Yang, J., Wang, Q., Kowalski, J., Freed, I., Murter, C., et al. (2010) Prognostic Significance of Tumorigenic Cells with Mesenchymal Features in Pancreatic Adenocarcinoma. Journal of the National Cancer Institute, 102, 340-351. http://dx.doi.org/10.1093/jnci/djp535

[44] Duong, H.Q., Hwang, J.S., Kim, H.J., Kang, H.J., Seong, Y.S. and Bae, I. (2012) Aldehyde Dehydrogenase 1A1 Confers Intrinsic and Acquired Resistance to Gemcitabine in Human Pancreatic Adenocarcinoma MIA PaCa-2 Cells. International Journal of Oncology, 41, 855-861.

[45] Jimeno, A., Feldmann, G., Suarez-Gauthier, A., Rasheed, Z., Solomon, A., Zou, G.M., et al. (2009) A Direct Pancreatic Cancer Xenograft Model as a Platform for Cancer Stem Cell Therapeutic Development. Molecular Cancer Therapeutics, 8, 310-314. http://dx.doi.org/10.1158/1535-7163.MCT-08-0924

[46] Wang, Z.W., Li, Y., Ahmad, A., Banerjee, S., Azmi, A.S., Kong, D. and Sarkar, F.H. (2011) Pancreatic Cancer: Understanding and Overcoming Chemoresistance. Nature Reviews Gastroenterology and Hepatology, 8, 27-33. http://dx.doi.org/10.1038/nrgastro.2010.188

[47] Sarkar, F.H., Li, Y., Wang, Z. and Kong, D. (2009) Pancreatic Cancer Stem Cells and EMT in Drug Resistance and Metastasis. Minerva Chirurgica, 64, 489-500.

[48] Wang, Z., Li, Y., Ahmad, A., Azmi, A.S., Kong, D., Banerjee, S. and Sarkar, F.H. (2010) Targeting miRNAs Involved in Cancer Stem Cell and EMT Regulation: An Emerging Concept in Overcoming Drug Resistance. Drug Resistance Updates, 13, 109-118. http://dx.doi.org/10.1016/j.drup.2010.07.001

[49] Zhang, S.N., Huang, F.T., Huang, Y.J., Zhong, W. and Yu, Z. (2010) Characterization of a Cancer Stem Cell-Like Side Population Derived from Human Pancreatic Adenocarcinoma Cells. Tumori, 96, 985-992.

[50] Wang, Z.W., Li, Y.W., Kong, D.J., Banerjee, S., Ahmad, A., Azmi, A.S., et al. (2009) Acquisition of Epithelial-Mesenchymal Transition Phenotype of Gemcitabine-Resistant Pancreatic Cancer Cells Is Linked with Activation of the Notch Signaling Pathway. Cancer Research, 69, 2400-2407. http://dx.doi.org/10.1158/0008-5472.CAN-08-4312

[51] Banerjee, S., Nomura, A., Sangwan, V., Chugh, R., Dudeja, V., Vickers, S.M. and Saluja, A. (2014) CD133 ${ }^{+}$Tumor Initiating Cells in a Syngenic Murine Model of Pancreatic Cancer Respond to Minnelide. Clinical Cancer Research, 20, 2388-2399. http://dx.doi.org/10.1158/1078-0432.CCR-13-2947

[52] Li, S.H., Fu, J., Watkins, D.N., Srivastava, R.K. and Shankar, S. (2013) Sulforaphane Regulates Self-Renewal of Pancreatic Cancer Stem Cells through the Modulation of Sonic Hedgehog-GLI Pathway. Molecular and Cellular Biochemistry, 373, 217-227. http://dx.doi.org/10.1007/s11010-012-1493-6

[53] Herrera, V.L., Decano, J.L., Tan, G.A., Moran, A.M., Pasion, K.A., Matsubara, Y. and Ruiz-Opazo, N. (2014) DEspR Roles in Tumor Vasculo-Angiogenesis, Invasiveness, CSC-Survival and Anoikis Resistance: A “Common Receptor Coordinator” Paradigm. PLoS ONE, 9, e85821. http://dx.doi.org/10.1371/journal.pone.0085821

[54] Kim, S.K., Kim, H., Lee, D.H., Kim, T.H., Kim, T., Chung, C., Koh, G.Y., Kim, H. and Lim, D.S. (2013) Reversing the Intractable Nature of Pancreatic Cancer by Selectively Targeting ALDH-High, Therapy-Resistant Cancer Cells. PLoS ONE, 8, e78130. http://dx.doi.org/10.1371/journal.pone.0078130

[55] Wang, X., Liu, Q., Hou, B., Zhang, W., Yan, M., Jia, H.M., et al. (2013) Concomitant Targeting of Multiple Key Transcription Factors Effectively Disrupts Cancer Stem Cells Enriched in Side Population of Human Pancreatic Cancer Cells. PLOS ONE, 8, e73942. http://dx.doi.org/10.1371/journal.pone.0073942

[56] Lonardo, E., Hermann, P.C., Mueller, M.T., Huber, S., Balic, A., Miranda-Lorenzo, I., et al. (2011) Nodal/Activin Signaling Drives Self-Renewal and Tumorigenicity of Pancreatic Cancer Stem Cells and Provides a Target for Combined Drug Therapy. Cell Stem Cell, 9, 433-446. http://dx.doi.org/10.1016/j.stem.2011.10.001

[57] Huang, J., Li, C., Wang, Y., Lv, H.Y., Guo, Y.L., Dai, H.R., et al. (2013) Cytokine-Induced Killer (CIK) Cells Bound with Anti-CD3/Anti-CD133 Bispecific Antibodies Target CD133 (High) Cancer Stem Cells in Vitro and in Vivo. Clinical Immunology, 149, 156-168. http://dx.doi.org/10.1016/j.clim.2013.07.006

[58] Himoudi, N., Morgenstern, D.A., Yan, M., Vernay, B., Saraiva, L., Wu, Y., et al. (2012) Human $\gamma \delta$ T Lymphocytes Are Licensed for Professional Antigen Presentation by Interaction with Opsonized Target Cells. Journal of Immunolo- 
gy, 188, 1708-1716. http://dx.doi.org/10.4049/jimmunol.1102654

[59] Braza, M.S. and Klein, B. (2013) Anti-Tumour Immunotherapy with V $\gamma 9 V \delta 2$ T Lymphocytes: From the Bench to the Bedside. British Journal of Haematology, 160, 123-132. http://dx.doi.org/10.1111/bjh.12090

[60] Oberg, H.H., Peipp, M., Kellner, C., Sebens, S., Krause, S., Petrick, D., et al. (2014) Novel Bispecific Antibodies Increase $\gamma \delta$ T-Cell Cytotoxicity against Pancreatic Cancer Cells. Cancer Research, 74, 1349-1360. http://dx.doi.org/10.1158/0008-5472.CAN-13-0675

[61] Visus, C., Wang, Y., Lozano-Leon, A., Ferris, R.L., Silver, S., Szczepanski, M.J., et al. (2011) Targeting ALDH ${ }^{\text {bright }}$ Human Carcinoma-Initiating Cells with ALDH1A1-Specific CD8 ${ }^{+}$T Cells. Clinical Cancer Research, 17, 6174-6184. http://dx.doi.org/10.1158/1078-0432.CCR-11-1111 
Scientific Research Publishing (SCIRP) is one of the largest Open Access journal publishers. It is currently publishing more than 200 open access, online, peer-reviewed journals covering a wide range of academic disciplines. SCIRP serves the worldwide academic communities and contributes to the progress and application of science with its publication.

Other selected journals from SCIRP are listed as below. Submit your manuscript to us via either submit@scirp.org or Online Submission Portal.
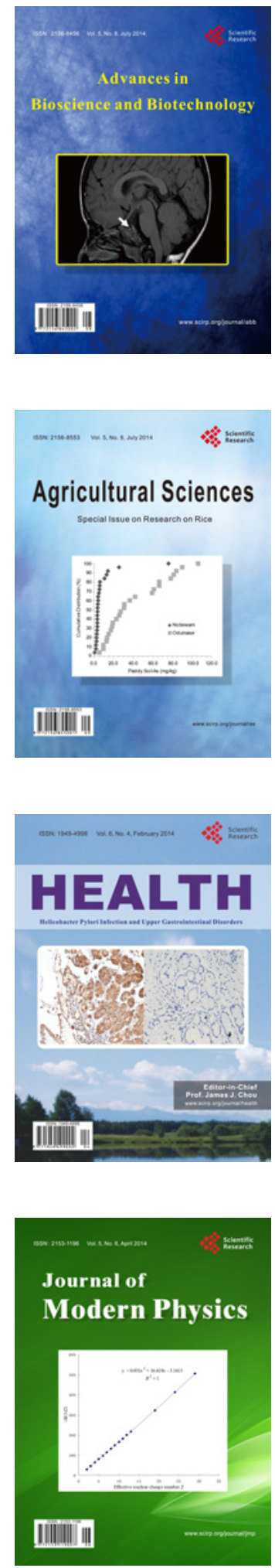
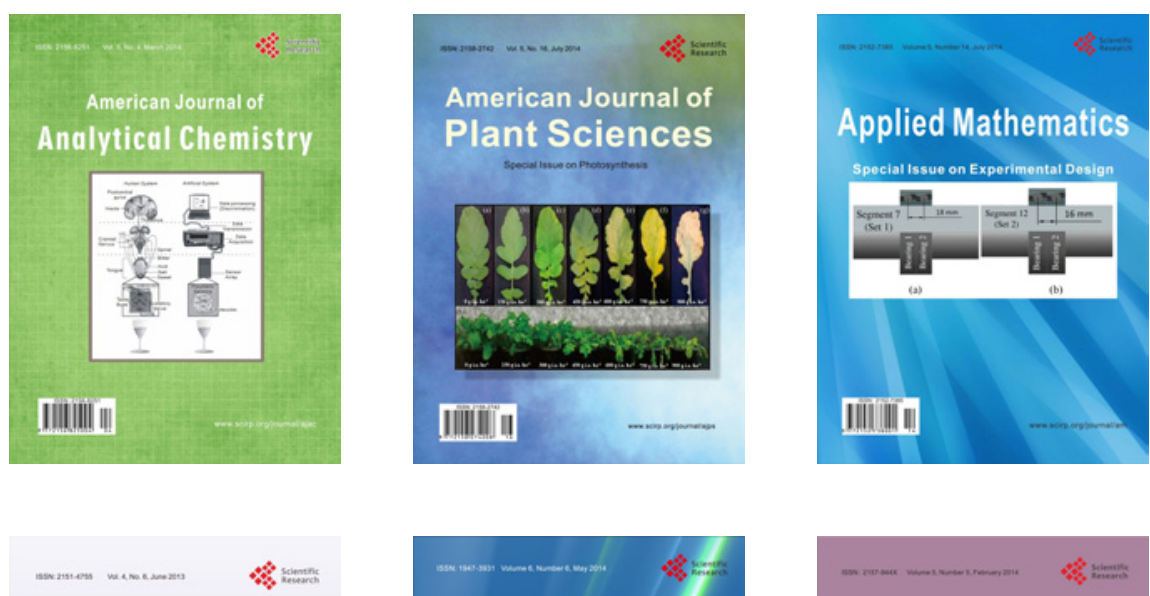

Creative Education
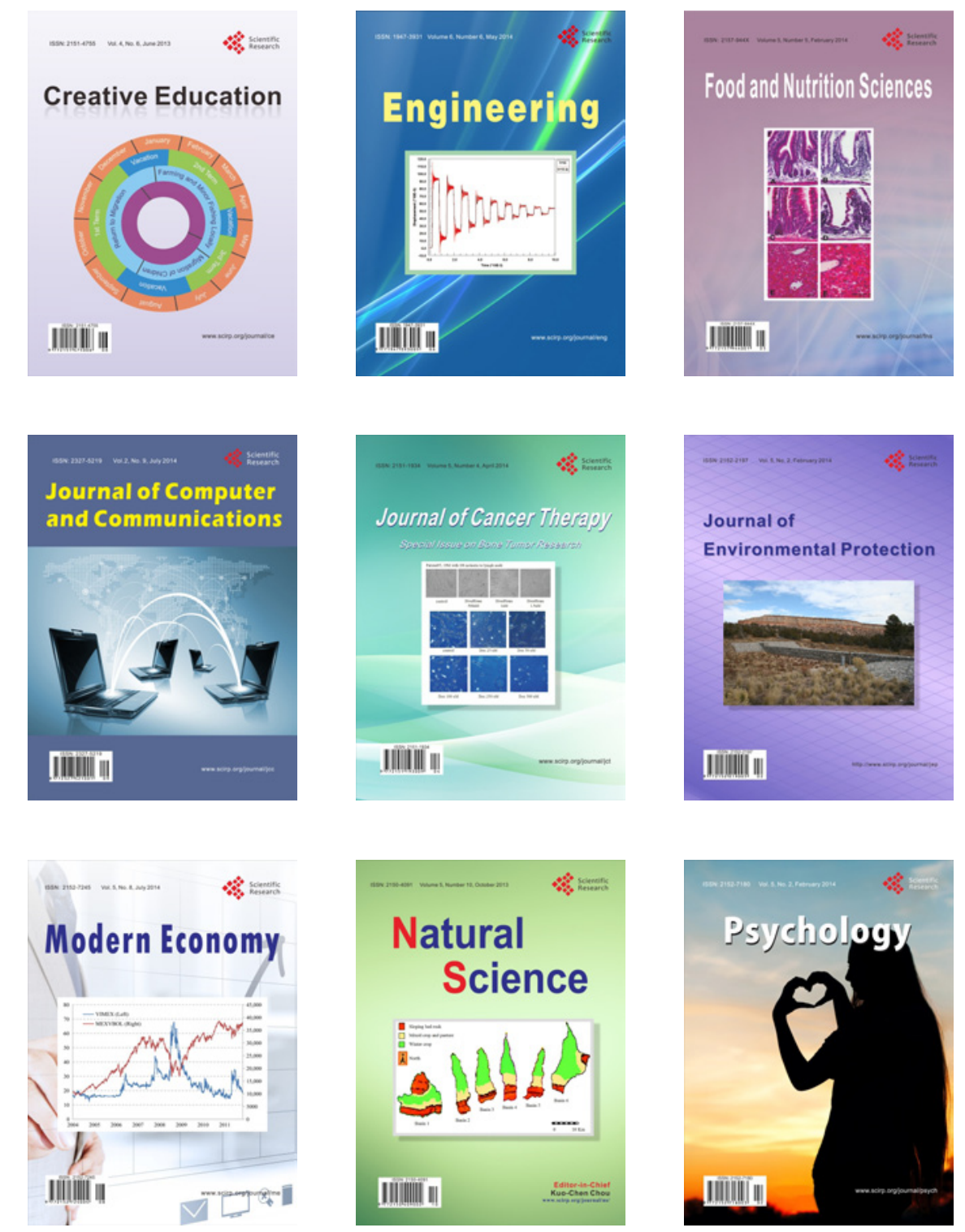